\title{
SUBSÍDIOS PARA O PLANEJAMENTO ESTRATÉGICO EM BIBLIOTECAS PÚBLICAS: ESTUDO DE CASO NA BIBLIOTECA MUNICIPAL DE PALHOÇA/SC
}

\author{
SUBSIDIES FOR STRATEGIC PLANNING IN A PUBLIC LIBRARY: \\ A CASE STUDY IN THE PALHOÇA/SC TOWN LIBRARY
}

\begin{abstract}
Jéssica Vilvert Klöppel ${ }^{1}$
Daniela Spudeit ${ }^{2}$

RESUMO

Este estudo teve como objetivo realizar um diagnóstico ambiental que sirva de subsídio para um planejamento estratégico em bibliotecas públicas e nesse trabalho foi relatada a aplicação na Biblioteca Pública Municipal de Palhoça Guilherme Wiethorn Filho. Caracteriza-se como pesquisa aplicada, exploratória e descritiva por procurar interferir na realidade da unidade de informação e ser uma maneira de conhecer e descrever o objeto de estudo com profundidade. O tratamento dos dados foi feito de acordo com a análise de conteúdo proposta por Bardin (2009), resultando na distribuição dos dados em seis categorias: função da Biblioteca Pública; gestão da Biblioteca; relação com a Prefeitura Municipal; estrutura física; acervo; e serviços. A partir do diagnóstico foi definido o mandato; a missão; os pontos fortes e fracos; as oportunidades e ameaças; as questões estratégicas; os obstáculos; e as propostas estratégicas adequadas. Ressalta-se a importância do planejamento estratégico para as bibliotecas públicas principalmente por conviverem com recursos limitados e atenderem um público heterogêneo com diversos perfis de usuários. Espera-se que esse trabalho sirva de referência para a construção de diretrizes e ações para outras bibliotecas públicas.
\end{abstract}

PALAVRAS-CHAVE: Planejamento estratégico. Bibliotecas públicas. Bibliotecas públicas - Diagnóstico.

ABSTRACT: This study had the objective to perform an environmental diagnosis that serves as subsidy for a strategic planning in public libraries and in this work it was reported the application in the Guilherme Wiethorn Filho Palhoça Town Public Library. It is characterized as applied research, exploratory and descriptive for trying to interfere in the unit reality of information and for being a way to know and describe the object of study in depth. The data processing was done according to the content analysis proposed by Bardin (2009), resulting in the distribution of data in six categories: function of the Public Library; Library management; relationship with the Town Hall; infrastructure; Library collection; and services. From this diagnosis it was defined the mandate; the mission; the strong and weak points; the opportunities and threats; the strategic issues; the obstacles; and the appropriate strategic proposition. The work emphasizes the importance of strategic planning for public libraries mainly for having to maintain itself with limited resources and serve a heterogeneous public with diverse user profiles. It is the expectation that this work serves as a reference for the construction of guidelines and actions for other public libraries.

KEYWORDS: Strategic planning. Public libraries. Public libraries - Diagnosis

\footnotetext{
${ }^{1}$ Bibliotecária e professora no curso de Biblioteconomia da UNIRIO - Universidade Federal do Estado do Rio de Janeiro. E-mail: danielaspudeit@gmail.com

2 Bibliotecária do Instituto Federal de Santa Catarina. E-mail: kikaph@gmail.com

Recebido em: 07/06/2014 - Aceito em: 19/04/2015
} 


\section{INTRODUÇÃO}

O acesso à informação é um direito de todos e, desde cedo, as pessoas aprendem com tudo o que está ao seu redor. Com o passar dos anos exerce-se o direito de ir à escola e ao longo da vida são as informações que movem a sociedade. Os meios de conseguir essas informações estão cada vez mais amplos e não é mais aceitável que parte da população fique desinformada, apesar de essa ser a realidade do país.

Como afirma Delors (2006), a comunicação entre as nações é um fator responsável pela mundialização, na qual as pessoas podem ter acesso às informações em qualquer parte do mundo, porém, esse fenômeno aumenta as desigualdades no momento em que há um monopólio cultural dos países mais desenvolvidos sobre as populações que não receberam preparação e educação de qualidade para criticar as informações recebidas.

De acordo com o Art. $8^{\circ}$ da Lei n ${ }^{\circ} 12.527$, "É dever dos órgãos e entidades públicas promover, independentemente de requerimentos, a divulgação em local de fácil acesso, no âmbito de suas competências, de informações de interesse coletivo ou geral por eles produzidas ou custodiadas" (BRASIL, 2011). A biblioteca pública, enquanto órgão mantido pelo governo se enquadra nessa situação e tem sua atividade fim na disseminação da informação para a sociedade.

Por meio da prática desse direito é que são formados cidadãos conscientes e críticos capazes de decidir seu futuro. $\mathrm{O}$ acesso às informações, de acordo com Santos, Bernardes e Rover (2012), é um exercício de democracia e deve ser feito com muita responsabilidade pelos representantes da população. E, muito além das informações sobre assuntos governamentais, é preciso conhecimento sobre diversas áreas para a formação do indivíduo.

Dessa forma, as unidades de informação assumem papel essencial na sociedade, sendo reconhecidas como fontes do saber. Essas condições deveriam modificar a visão que a população em geral tem das bibliotecas, pois elas “[...] deixam de ser apenas um local onde se dispõe de livros, quebrando fronteiras através de redes de comunicação, conectando seus usuários ao mundo do conhecimento independente de onde eles estejam" (ROMANI; BORSZCZ, 2006, p. 8).

Nas bibliotecas públicas os trabalhos de seleção, tratamento e disseminação da informação tornam-se mais complexo devido ao público heterogêneo que ela atende. Mais que a disseminação do conhecimento, a biblioteca pública deve ser a "[...] força viva para a educação, a cultura e a informação", como determina o Manifesto da IFLA/UNESCO sobre Bibliotecas Públicas (1994).

O gestor da biblioteca pública precisa estar atualizado nos mais diversos assuntos, conhecer os perfis dos usuários para, a partir disso, planejar as aquisições, as atividades propostas e os recursos empregados. Além de ter um público alvo amplo, a biblioteca pública conta geralmente com recursos financeiros escassos e incertos, devido à mudança de governo e questões políticas envolvidas nas prefeituras e demais órgãos. Por isso, é imprescindível 
que os gestores das bibliotecas públicas se preocupem em ter um bom planejamento, para evitar desperdícios e trabalhar com eficiência e eficácia.

A elaboração de um planejamento estratégico é bastante difundida em unidades de informação por meio de estudos, entretanto, ainda não é uma prática comum na gestão dessas instituições, seja por falta de conhecimento, recursos ou mesmo por falta de pessoas, pois é comum encontrar um único bibliotecário, responsável por todos os serviços nas unidades de informação.

Porém, é necessária a consciência de que "[...] o tempo empregado no processo de planejamento certamente é menor e mais produtivo do que o tempo perdido com processos improvisados, em que as decisões estariam sempre sujeitas a soluções imediatistas" (ALMEIDA, 2005, p. 2). O planejamento estratégico deve ser um processo contínuo e flexível, permitindo revisões de acordo com as mudanças ocorridas nos ambientes interno e externo, mas sempre alinhado com os objetivos da unidade de informação.

Essa realidade está presente nas bibliotecas públicas e se aplica à Biblioteca Pública Municipal de Palhoça Guilherme Wiethorn Filho, objeto de estudo desta pesquisa, onde não são realizados estudos com os usuários, tampouco são registradas constantemente as estatísticas de visitas e circulação de materiais. Os relatórios são baseados nos empréstimos e registro de uso do computador, o que não representa a realidade, pois várias pessoas vão apenas para tirar dúvidas ou permanecer no local, e boa parte delas não assina o livro de presença que fica em um local não muito visível.

Acredita-se que com o planejamento das ações, da utilização de recursos e do espaço físico, a Biblioteca Pública Municipal Guilherme Wiethorn Filho poderia atrair mais usuários e utilizar de forma eficiente e eficaz os recursos disponíveis. Nessa linha, a biblioteca foi estudada em todos os seus aspectos para a elaboração de um planejamento estratégico, que atua em plano global e em sintonia com os ambientes interno e externo da organização.

A história da Biblioteca Pública Municipal Guilherme Wiethorn Filho começou em 1973 quando foi criada pelo prefeito, Odílio José de Souza, porém, por motivos de planejamento da sua estrutura física e organização das atividades, a instituição foi inaugurada somente em 1975, seu nome é uma homenagem a um professor que prestou grandes serviços para Palhoça (PAULO, 2005).

Ao longo de sua trajetória, a biblioteca passou por vários problemas estruturais, físicos, humanos e materiais, por isso acredita-se que a construção de um planejamento estratégico poderá subsidiar a tomada de decisões dos gestores para que a mesma alcance resultados mais eficientes junto à comunidade em que atua. 


\section{BIBLIOTECAS PÚBLICAS E O ACESSO À INFORMAÇÃO: UM DIREITO DO CIDADÃO}

A sociedade da informação definida como "[...] uma nova era em que a informação flui a velocidades e em quantidades há apenas poucos anos inimagináveis, assumindo valores sociais e econômicos fundamentais" (TAKAHASHI, 2000, p. 3) e trouxe consigo a afirmativa de que a informação está ligada ao poder. Esse momento caracteriza-se pela importância que a informação assume em todos os seguimentos da sociedade desde a interação entre os indivíduos até as influências políticas, quando há disseminação e acesso a ela, o que pode ser facilitado por meio das tecnologias de informação e comunicação.

Mais do que ter acesso à informação de qualidade, o desenvolvimento de um pensamento crítico, para produzir novas informações é essencial, e esse processo de construção do conhecimento requer prática. O desafio dessa configuração da sociedade é fazer com que todas as pessoas estejam inseridas nesse contexto de grande circulação de informações. Todavia, apesar dos esforços dos países e o rápido avanço das tecnologias, não se pode ignorar o fato de que muitas pessoas ainda não possuem acesso nem mesmo a energia elétrica, telefone e principalmente a internet. Para suprir essa lacuna, devem ser criados mecanismos para facilitar o acesso à informação e estimular seu uso. A biblioteca pode disponibilizar materiais em diversos suportes e com diferentes visões sobre um conteúdo, permitindo que seja criado um contexto e desenvolvido o pensamento crítico nos cidadãos.

Nessa linha, Milanesi (1986) cita três forças que detêm e repassam informação e que poderiam ir contra o sistema massificador: a escola, os meios de comunicação e a biblioteca enquanto centro de informação. Corroborando com o conceito de que informação é poder, essas três forças poderosas que detém a informação deveriam ser respeitadas, pois, algumas escolas e bibliotecas se esforçam para viabilizar a transformação da informação em conhecimento para os cidadãos, mas não são valorizadas. Os meios de comunicação, principalmente a televisão e a internet, recebem atenção do público, mas o valor comercial se sobrepõe à disseminação de informações pertinentes à população.

Além destes, outros canais têm a competência de reunir e disseminar informações como as unidades de informação que de acordo com Barbalho e Beraquet (1995, p. 63) são "[...] arquivos, discotecas, filmotecas, hemerotecas, mapotecas, pinacotecas, os diversos tipos de centros de informação, os museus e as bibliotecas que se dedicam às atividades de informação". Isso mostra que as oportunidades de acesso à informação são variadas para satisfazer as necessidades de todos os perfis de usuários, sendo que as mais tradicionais são as bibliotecas. Cada categoria de biblioteca tem suas atividades e públicos específicos, podendo ser públicas ou privadas. No entanto, a finalidade de disseminar a informação e tornar a instituição um ambiente dinâmico é pertinente a todas elas.

Uma maneira de fazer com que a biblioteca seja reconhecida como parte integrante da sociedade é torná-la um local de lazer e entretenimento, explorando seu potencial cultural. Por estar inserida na comunidade, além de trazer informações, deve preservar a memória 
cultural local, sua história, e valorizar seus artistas. Segundo a Fundação Biblioteca Nacional (2000, p.19), a biblioteca pública caracteriza-se como “[...] instituição cultural, através da promoção do acesso à cultura e do fortalecimento da identidade cultural da comunidade local e nacional".

As bibliotecas públicas, assim como as demais, têm a função principal de organizar, disseminar e mediar a informação, promovendo o acesso democrático a ela para todas as pessoas. Algumas funções também são comuns aos diferentes tipos de bibliotecas, e de acordo com Romani e Borszcz (2006, p. 15), as principais estão "[...] relacionadas à gestão e ao tratamento técnico da coleção; atividades de assistência ao cliente; serviços de informação tecnológica; serviço de apoio a outras unidades de informação (salas de leitura)". A maneira como essas funções são distribuídas depende da demanda: em algumas bibliotecas são divididas em setores e em outras, por falta de funcionários especializados, são realizadas por um pequeno grupo e, às vezes, por uma única pessoa.

Todos os serviços e produtos de uma biblioteca deveriam ser desenvolvidos para satisfazer as necessidades dos usuários, não somente daqueles que vêm até a biblioteca, mas também daqueles que deveriam vir e que fazem parte do escopo da instituição, seja ela uma biblioteca pública, escolar, comunitária, especializada ou universitária.

O público-alvo das bibliotecas públicas é o mais heterogêneo entre todas as categorias, pois inclui todas as pessoas que vivem na comunidade em que está inserida, abrangendo todo um bairro, município ou estado. Pode ser frequentada por estudantes de todos os níveis de escolaridade, trabalhadores, idosos, donas de casa, pessoas de todas as idades, com hábitos e ocupações distintos, em maior ou menor número, dependendo do perfil da comunidade. Milanesi (1986, p.11) afirma que "a biblioteca pública, no rigor de sua denominação, deve estar aberta a todos os públicos de uma determinada coletividade". Não deve se especializar somente em um público e deixar os outros sem suas informações. Muito embora, a maior parte dos frequentadores serem estudantes, a população em geral do município se caracteriza como usuário potencial.

Segundo Milanesi (1986), devem ser feitas ações inclusive para os analfabetos, para que tenham oportunidade ao acesso à informação para se alfabetizar. Nesse sentido:
A biblioteca pública, em seu verdadeiro sentido de atuação, livre, aberta democrática, socializadora, que ao mesmo tempo em que cuida da preservação da memória investe na construção do conhecimento e soma esforços para que transforme e seja transformada para e pelo usuário, e que, em razão deste, possa se tornar um ambiente vivo e efervescente de cultura (BERNARDINO; SUAIDEN, 2011, p. 34).

Mais do que um local para pesquisar, a biblioteca pública é a oportunidade para todas as pessoas, sem restrições, construírem conhecimento e desenvolverem sua cidadania.

Dessa forma, a biblioteca contribui para a formação de cidadãos críticos, que reflitam sobre as decisões que serão tomadas em todos os aspectos de sua vivência. Segundo a 
Fundação Biblioteca Nacional (2000), a biblioteca é um elo entre a necessidade de informação e os recursos disponíveis, é a oportunidade que as pessoas da comunidade têm para o livre acesso à informação e a possibilidade de construírem novos conhecimentos. Nesse sentido, para cumprir seu papel,

[...] uma biblioteca pública deve constituir-se em um ambiente realmente público, de convivência agradável, onde as pessoas possam se encontrar para conversar, trocar ideias, discutir problemas, auto-instruir-se e participar de atividades culturais e de lazer (FUNDAÇÃO BIBLIOTECA NACIONAL, 2000, p.17).

Como local público e depositária de informações, a biblioteca é o único meio de acesso à informação de qualidade para muitas pessoas, principalmente as de baixa renda. Por isso, deve estar ao alcance de todos, oferecendo serviços adequados a realidade do seu público real e potencial, promovendo a integração da sociedade, complementando o que é aprendido na educação formal e desenvolvendo ações culturais e de lazer para todos os perfis de usuário.

Por concentrar inúmeras funções, a biblioteca pública necessita de planejamento e gerenciamento. Para orientar na elaboração do planejamento, há vários documentos norteadores para auxiliar na organização de produtos, serviços e demais atividades da biblioteca, profissional responsável recorra a eles e adapte seu conteúdo a realidade da instituição que gerencia (FUNDAÇÃO BIBLIOTECA NACIONAL, 2000).

O planejamento requer conhecimento e dedicação para melhor distinguir realidade da biblioteca e definir claramente seus objetivos. A finalidade deve estar delineada a fim de não se perder o foco durante o desenvolvimento dos planos de ação. Não será possível abranger todos os assuntos para atender as necessidades específicas de cada pessoa, é imprescindível definir prioridades. De acordo com a Fundação Biblioteca Nacional (2000, p. 28),

\footnotetext{
A definição de projetos e serviços baseados nas técnicas de segmentação de mercado e o estabelecimento de prioridades na implementação destes projetos evitam que o responsável pela biblioteca tente abarcar toda a gama de serviços possíveis de serem oferecidos hoje por uma biblioteca pública.
}

A falta de planejamento se intensifica levando em consideração os escassos recursos que geralmente são destinados às bibliotecas públicas, quando existem. A Fundação Biblioteca Nacional (2000) sugere ainda que o gestor da biblioteca tenha um bom relacionamento com os políticos e sua instituição mantenedora.

Dessa forma, poderá mostrar a importância dos serviços prestados e atrairá mais pessoas comprometidas com seus ideais. Porém, esse contato pode ser dificultado por questões políticas, então para não depender apenas de decisões políticas. O bibliotecário deve firmar parcerias com outras instituições públicas e privadas, bem como buscar recursos por meio de editais provenientes de políticas públicas de incentivo à cultura, ao livro e às bibliotecas, por exemplo. 
Frente aos desafios que uma biblioteca pública encontra para desempenhar sua função social, bem como disponibilizar materiais adequados para pesquisa e informações úteis a comunidade, e cumprir seu compromisso com a cultura, a informação e a construção do conhecimento, seu gestor deve estar preparado e disposto a cumprir seu papel. Para tal, ele precisa de um instrumento que o oriente como utilizar, da melhor forma, os recursos disponíveis para disponibilizar produtos e serviços que vão de encontro com as necessidades do seu público alvo, bem como para atender as novas demandas da biblioteca. Neste sentido, para que as bibliotecas públicas atinjam seus objetivos, é necessário ter um planejamento bem estruturado e atualizado constantemente.

Assim, pode-se garantir o acesso à informação para a população, com serviços adequados, otimizando os recursos disponíveis. Todavia, mais do que planejar, é preciso saber pensar estrategicamente, conhecer os conceitos, finalidades e etapas do planejamento, como será tratado na próxima seção.

\section{PLANEJAMENTO ESTRATÉGICO EM UNIDADES DE INFORMAÇÃO}

Para realizar ações é necessário planejar, pois tomar decisões imediatistas, sem visão holística, pode causar grandes prejuízos. O planejamento envolve pensar nas consequências de uma ação e analisar todos os fatores envolvidos. De maneira mais objetiva, "[...] o planejamento pode ser conceituado como um processo [...] desenvolvido para o alcance de uma situação futura desejada, de um modo mais eficiente, eficaz e efetivo, com a melhor concentração de esforços e recursos pela empresa" (OLIVEIRA, 2010, p.4).

É comum o pensamento de que somente as organizações que visam ao lucro necessitam de planejamento. Porém, todos os setores encontram-se extremamente interconectados e a sobrevivência de uma instituição depende de diversos fatores advindos de organizações que visam ao lucro ou não. Assim como as empresas privadas, as organizações públicas e filantrópicas estão em contato direto com diferentes tipos de mercados e públicos, por isso devem estar atentas em como atrair o público, motivar seus funcionários e adquirir recursos (KOTLER, 1978). Como organização pública, sem fins lucrativos, a biblioteca pública, visando angariar recursos, deve, sobremaneira, planejar suas ações presentes visando à prospecção do futuro, levando em consideração o ambiente interno e externo, fazendo assim, um planejamento estratégico.

Apesar de não possuir um lucro financeiro, o retorno conseguido pela unidade de informação alcançando seu objetivo de disseminar as informações, é demonstrado com a construção de novos conhecimentos. Ao satisfazer as necessidades dos clientes, a instituição mostra seu valor diante da comunidade, atrai novos investimentos, pode inovar na promoção de produtos e serviços e, consequentemente, conquistar novos clientes.

Além do objetivo de atender e criar demandas, o planejamento estratégico em unidades de informação é necessário para gerenciar seus recursos, muitas vezes escassos, e 
assim, poder continuar com sua finalidade de suprir a necessidade informacional de seus usuários. Assim, a preocupação em administrar estrategicamente também gerou estudos na área da biblioteconomia.

De acordo com Barbalho e Beraquet (1995) a diferença básica entre o planejamento tradicional e o planejamento estratégico é que o primeiro se preocupa com o ambiente interno da empresa, levando em consideração ações anteriores, já o estratégico envolve a análise do ambiente externo, com visão de longo prazo, a fim de prever situações futuras. De acordo com as autoras, "Busca-se, dessa forma, antever o futuro, trazendo-o para o presente e indagando-se o que deve a organização estar fazendo hoje a fim de melhor preparar-se para as incertezas e turbulências previsíveis que poderão afetar as suas atividades" (BARBALHO, BERAQUET, 1995, p. 12).

Assim como afirmam os autores da administração, o planejamento, para que seja viável e auxilie nas futuras tomadas de decisão, deve partir da alta administração e envolver os demais funcionários. Com todos os pontos bem definidos, Barbalho e Beraquet (1995, p. 24) afirmam que "[...] podemos considerar o Planejamento Estratégico como a utilização eficaz dos meios disponíveis na organização para exploração de condições favoráveis existentes no meio-ambiente externo e interno".

Almeida (2005) confirma esse fato e complementa com as etapas do planejamento estratégico. Começa pela análise das condições presentes para determinar formas de atingir um futuro desejado. Isso implica escolher metas, prever, influenciar e controlar a natureza e a direção de mudanças e, finalmente, rever criticamente os resultados obtidos, avaliando a eficiência e eficácia dos programas e atividades em relação aos objetivos e metas fixados. (ALMEIDA, 2005).

Em linhas gerais, o planejamento estratégico em unidades de informação tem a mesma finalidade e características do que é realizado nas demais organizações. Deve partir da alta administração e gerentes que, segundo Barbalho e Beraquet (1995, p. 12), “[...] buscam estabelecer de forma integrada o rumo e a direção a ser seguida pela organização, de forma a incluir nesse processo o maior grau possível de interação com o ambiente". Na mesma linha, , Maciel e Mendonça (2006, p. 59 apud HOBROCK, 1991) $)^{3}$ explica que "o Planejamento Estratégico é um conjunto de princípios e processos que possibilitam aos gerentes de bibliotecas, em qualquer nível, criar e controlar o seu futuro".

No caso específico das unidades de informação, os gerentes e principais responsáveis precisam ter formação na área em que estão atuando. Os bibliotecários deveriam assumir esse espaço, procurando conhecimentos técnicos e administrativos para tal função. Aqueles que não receberam esses conhecimentos no ensino superior podem procurar por cursos de pósgraduação ou outros cursos de educação continuada para adquirir formação e capacitação na área de gestão de unidades de informação.

${ }^{3}$ HOBROCK, Brice G. Creating your library's future through effective strategic planning. Journal of Library Administration, v.14, n.2, p.37-57, 1991. 
O gestor de unidades de informação deve conhecer muito bem a instituição onde atua, a entidade mantenedora e o meio no qual está inserida. Como afirma Almeida (2005, p. 5):

O primeiro objetivo do profissional de informação na função de planejador consiste, portanto, em interpretar corretamente a missão institucional e fixar objetivos para o serviço de informação que colaboram para o cumprimento daquela missão e ofereçam soluções adequadas aos problemas identificados.

Os princípios da eficiência, eficácia e efetividade também devem ser observados nas unidades de informação, e assumem maior importância nas entidades mantidas pelo setor público ou organizações não governamentais (ONGs). Nesses casos, a limitação de recursos é um obstáculo que pode ser vencido com o comprometimento que a comunidade e os funcionários têm com a biblioteca. A utilização racional dos materiais, participação em editais de organizações públicas e privadas, e a divisão de tarefas são alguns exemplos de ações que podem ser realizadas para alcançar os objetivos propostos com os recursos disponíveis. Por meio delas é possível verificar que:

\section{Planejar estrategicamente implica em integrar a Unidade de Informação aos processos sócio-econômicos do ambiente macro e micro da organização em que está subordinada, em consonância com as necessidades de informações que impliquem no seu desenvolvimento eficaz. (BARBALHO; BERAQUET, 1995, p. 44)}

Para garantir eficiência e eficácia a sua elaboração e implementação, “[...] o Planejamento Estratégico deve ser integrado em todos os setores da Unidade de Informação, sendo, portanto necessário que todos os funcionários conheçam e participem das estratégias estabelecidas" (BARBALHO; BERAQUET, 1995, p. 45). Deve haver participação integral de todos os funcionários, todas as opiniões devem ser ouvidas sem sair do foco do planejamento e dos anseios da biblioteca. Com a participação em todas as etapas do planejamento, a chance de aceitação é maior, pois os funcionários irão conhecer o que está acontecendo e se sentirem realmente participantes. O responsável deve ter atitude proativa e passar isso aos demais, criando uma motivação para que o planejamento estratégico seja realizado com o empenho de todos.

O conhecimento do que foi proposto e a participação desde o início da construção do planejamento faz com que as pessoas se interessem mais em participar, e de acordo com Maciel e Mendonça (2006, p. 61), “Todos os participantes do processo devem entendê-lo antes para participar depois, ou seja, precisam ser minuciosamente esclarecidos sobre os estudos e propostas em cogitação".

Para dar suporte ao planejamento e descrever minuciosamente as ações que serão realizadas, Almeida (2005) indica um plano que, segundo ela, "[...] é um evento intermediário entre o processo de planejamento e o processo de implementação do planejamento". Nele constarão as ações que serão realizadas, o período, como acontecerão, quem realizará cada função e os recursos necessários. Dessa forma, o plano "[...] oferece uma estrutura de referência para a tomada de decisão e é um compromisso com a mudança" (ALMEIDA, 2005, p. 4). 
A fim de gerar o resultado esperado o planejamento estratégico em unidades de informação também deve seguir algumas etapas descritas por diversos autores, que envolvem basicamente os mesmos passos, com algumas diferenças de acordo com a evolução dos termos, inclusão ou retirada deles. As etapas que devem ser seguidas em unidades de informação são semelhantes às que se aplicam as demais organizações. De acordo com Barbalho e Beraquet (1995), as etapas do planejamento tradicional são: diagnóstico, definição do objeto do planejamento, formulação, implantação, controle e avaliação. Almeida (2005) descreve os processos do planejamento com a definição do objeto, seguido do diagnóstico, elaboração do plano, implementação, acompanhamento e adaptações.

É possível perceber que várias etapas são mencionadas por Barbalho e Beraquet (1995) apenas com a inversão da etapa do diagnóstico com a definição do objeto de planejamento e variação dos demais termos empregados, mas que se referem ao mesmo processo. Essas etapas não precisam obedecer uma ordem rigorosa, pois variam de acordo com a cultura organizacional e se complementam, já que as informações obtidas são necessárias para a realização das etapas seguintes. A avaliação deve ser realizada durante todo o processo, para que ele seja flexível e passível de ajustes no decorrer da elaboração e implementação.

Para que as etapas do planejamento estratégico possam ser realizadas de acordo com os objetivos da instituição, com o emprego de metas e sem perder o foco, como já foi citado anteriormente e demonstrado em outras pesquisas, é necessário empregar uma metodologia, como as sugeridas por Oliveira (2010), Almeida (2005), Barbalho e Beraquet (1995), entre outros.

Nesta pesquisa, optou-se por utilizar a metodologia proposta por Barbalho e Beraquet (1995, apud BRYSON, 1989) ${ }^{4}$, que envolve a definição do mandato e missão, análise do ambiente externo, análise do ambiente interno, formulação de questões estratégicas, reconhecimento dos obstáculos e o desenvolvimento de propostas estratégicas.

\section{PROCEDIMENTOS METODOLÓGICOS}

Para atingir o objetivo de apresentar diretrizes para elaboração de um planejamento estratégico a ser aplicado em bibliotecas públicas tendo como estudo de caso a Biblioteca Pública Municipal de Palhoça/SC, esse trabalho se caracteriza como uma pesquisa aplicada que busca conhecer as necessidades da instituição e da comunidade onde a biblioteca está inserida para propor um planejamento estratégico para a mesma. Nesse caso, as soluções serão propostas com a intenção de aplicá-las, mas não há garantias de que isso efetivamente acontecerá.

Baseada na metodologia de Gil (2010), a pesquisa é classificada quanto aos fins como exploratória e descritiva. Quanto aos meios, é uma pesquisa bibliográfica em fontes primárias

\footnotetext{
${ }^{4}$ BRYSON, John M. Strategic planning for public and nonprofit organizations. San Francisco: Jossey-Bass Publishers, 1989.
} 
e secundárias com a intenção de definir as unidades de informação, mais especificamente as bibliotecas públicas, seus conceitos, características e finalidades, a gestão das unidades de informação e o planejamento estratégico, suas características, etapas, metodologias e finalidades.

Além disso, se caracteriza como levantamento, porque opiniões e interesses da população estudada foram levantados por meio de questionários aplicados em usuários internos e externos da Biblioteca. Entre os primeiros estão os funcionários da biblioteca e da Prefeitura Municipal de Palhoça, à qual a unidade de informação está subordinada. No total foram 32 entrevistados, distribuídos em oito funcionárias da Biblioteca Pública, doze usuários reais que frequentaram a biblioteca no período da pesquisa, dois funcionários da prefeitura e dez representantes de associações de bairro que se prontificaram em participar da pesquisa para compor o universo dos usuários potenciais.

Para complementar as informações e auxiliar na análise dos dados foi utilizada a pesquisa documental em relatórios, além de documentos oficiais e não oficiais relacionados à Biblioteca Pública Municipal de Palhoça Guilherme Wiethorn Filho.

A abordagem adotada para o tratamento dos dados coletados foi qualitativa porque o corpus pesquisado é reduzido e específico e, esse tipo de análise é mais maleável na utilização dos dados, possibilitando inferências não pela frequência, mas pelo peso que o termo tem no contexto da pesquisa (BARDIN, 2009). Os dados coletados foram categorizados para facilitar a análise da seguinte forma: função da biblioteca pública; gestão da biblioteca pública; relação com a Prefeitura Municipal; estrutura física; acervo; e serviços. Algumas categorias foram subdividas para facilitar a análise e o tratamento dos dados e tornar possíveis inferências a partir da análise de dados.

\section{DIRETRIZES PARA O PLANEJAMENTO ESTRATÉGICO EM UMA BIBLIOTECA PÚBLICA}

A pesquisa realizada com a comunidade, e com os usuários, com colaboradores da Biblioteca e da Prefeitura foi um instrumento muito importante para conhecer o ambiente e traçar um diagnóstico do contexto no qual a unidade de informação está inserida. As respostas foram analisadas sob a luz da literatura permitindo comparar as situações retratadas na literatura com a realidade atual da Biblioteca Pública Municipal de Palhoça Guilherme Wiethorn Filho para que fossem traçadas as estratégias em um plano de ação.

A partir da análise dos dados coletados por meio das entrevistas foi possível elaborar as sugestões para incorporar um planejamento estratégico para a unidade de informação pesquisada. As sugestões propostas para o plano de ação foram construídas com base na metodologia apresentada por Barbalho e Beraquet (1995, apud BRYSON, 1989) ${ }^{5}$, que

\footnotetext{
${ }^{5}$ BRYSON, John M. Strategic planning for public and nonprofit organizations. San Francisco: Jossey-Bass Publishers, 1989.
} 
envolve a definição do mandato, da missão, a análise dos ambientes externo e interno, a formulação de questões estratégicas, o reconhecimento dos obstáculos e o desenvolvimento de propostas estratégicas.

\subsection{Definição do Mandato e da Missão}

A definição do mandato e da missão da unidade de informação é o primeiro passo para a elaboração das propostas estratégicas. Esses elementos expõem de maneira direta a finalidade da criação da instituição, quem são seus stakeholders, e devem estar alinhadas aos seus objetivos e valores.

O mandato deve ser redigido de acordo com o documento de criação da biblioteca. No entanto, no documento de criação da instituição estudada não há uma definição explícita, e então foi elaborado o seguinte mandato: "Ser um ambiente cultural de obtenção, disseminação e criação do conhecimento para os cidadãos palhocenses, além de preservar a memória e a cultura local".

A missão de uma biblioteca deve explicitar os principais serviços que deve realizar, seu público alvo e de que maneira realizará suas funções. Com base no regulamento vigente da Biblioteca Pública Municipal de Palhoça de 1984 é sugerida a seguinte Missão: "Proporcionar o livre acesso aos registros do conhecimento para os moradores do Município de Palhoça por meio de obras didáticas, técnicas, literárias e especializadas nos diversos suportes, e com a realização de projetos culturais a fim de desenvolver o pensamento crítico nos cidadãos".

\subsection{Diagnóstico interno e externo}

A partir dos dados coletados foi possível identificar pontos fortes e fracos da Biblioteca, bem como as ameaças e oportunidades para que suas atividades continuem sendo realizadas.

Os pontos fortes encontrados nos depoimentos por meio da coleta de dados foram:

- Autonomia para tratamento técnico do acervo;

- Cordialidade das funcionárias;

- Possuir uma gestora com formação adequada;

- Oferecer serviço de reprografia;

- Bom aproveitamento dos poucos recursos existentes para continuar oferecendo os serviços e realizando eventos pontuais durante o ano;

- Participação efetiva de algumas escolas nos eventos realizados; 
- Formação de parcerias para a realização dos eventos;

- Utilização do jornal local para a divulgação dos serviços e eventos

Os pontos fracos verificados foram:

- Falta de registro constante dos dados estatísticos da biblioteca;

- Falta de suporte técnico para a manutenção dos computadores;

- Falta de integração e comunicação entre os membros da equipe;

- Indefinição na delegação de tarefas aos funcionários;

- Poucas oportunidades para capacitação das funcionárias;

- Possuir apenas uma bibliotecária atuando na Biblioteca;

- Falta de pró-atividade dos colaboradores;

- Não possuir bebedouros disponíveis para os usuários;

- Falta de investimento periódico em acervo, inviabilizando sua atualização e ampliação;

- Não ter assinatura de jornais de circulação estadual e nacional, nem de periódicos de diversas áreas;

- Falta de divulgação dos serviços;

- Inexistência de uma página na internet;

- Não oferecer informativos aos usuários sobre as normas da Biblioteca e os serviços oferecidos;

- Regulamento da Biblioteca desatualizado;

- Não possuir uma política de desenvolvimento de coleções oficial;

- Estar instalada em espaço alugado, em área com pouca circulação de pessoas;

- Controle manual da circulação de materiais;

- Falta de integração com outras instituições vinculadas à Prefeitura Municipal, como escolas e a Faculdade Municipal de Palhoça

Nos depoimentos coletados com os representantes das comunidades e usuários reais da biblioteca foram verificadas as ameaças e oportunidades. Dentre as ameaças cita-se: 
- Escassez de recursos públicos devido a falta de planejamento da Prefeitura;

- A inexistência de uma Secretaria de Cultura ou Fundação Municipal de Cultura com autonomia financeira, à qual a Biblioteca Pública deveria estar vinculada;

- Não reconhecimento da importância da Biblioteca Pública e suas atividades por parte da Prefeitura;

Nas oportunidades de melhoria verificou-se:

- A existência de Associações de Bairro que atendem a maior parte do município;

- Reconhecimento da importância da informação para os cidadãos pelas comunidades;

- Existência de muitas escolas no Município;

- Lançamento de editais de instituições públicas e privadas para o investimento em bibliotecas e áreas afins.

\subsection{Questões estratégicas, obstáculos e propostas estratégicas}

As propostas estratégicas foram elaboradas de acordo com o diagnóstico da Biblioteca Pública Municipal de Palhoça e a análise dos ambientes externo e interno, alinhadas as questões estratégicas e aos obstáculos identificados. No quadro a seguir são apresentadas algumas questões estratégicas, com seus respectivos obstáculos e propostas, os recursos envolvidos, os responsáveis sobre cada uma delas e o prazo para sua concretização, sendo que este pode ser de curta, média ou longa duração.

As propostas de curto prazo geralmente envolvem os recursos já existentes e de fácil acesso na biblioteca, podendo ser executadas em dias ou semanas. As de médio prazo necessitam de captação de recursos na unidade mantenedora, por meio de licitações ou compra direta, ou de maneira alternativa, por meio de editais, concursos, entre outros, e são realizadas em alguns meses. Já as propostas de longo prazo necessitam da captação de recursos e participação na previsão orçamentária anual ou de governo da Prefeitura Municipal e podem levar anos para serem concretizadas.

QUADRO 1 - Questões estratégicas, obstáculos e propostas

\begin{tabular}{|c|c|c|c|c|c|}
\hline $\begin{array}{c}\text { Questões } \\
\text { Estratégicas }\end{array}$ & Obstáculos & Estratégia & $\begin{array}{c}\text { Origem dos } \\
\text { recursos }\end{array}$ & $\begin{array}{l}\text { Responsávei } \\
\text { S envolvidos } \\
\end{array}$ & Prazo \\
\hline \multirow{2}{*}{$\begin{array}{l}\text { Como obter } \\
\text { informações reais } \\
\text { e atualizadas para } \\
\text { o planejamento } \\
\text { dos serviços } \\
\text { oferecidos pela } \\
\text { Biblioteca? }\end{array}$} & $\begin{array}{l}\text { Não aprovação } \\
\text { de um } \\
\text { regulamento } \\
\text { atualizado }\end{array}$ & $\begin{array}{l}\text { Atualizar o Regulamento } \\
\text { da Biblioteca }\end{array}$ & Biblioteca & $\begin{array}{l}\text { Gestor da } \\
\text { Biblioteca }\end{array}$ & Curto \\
\hline & $\begin{array}{l}\text { Não aprovação } \\
\text { uma política de } \\
\text { desenvolvimento } \\
\text { de coleções }\end{array}$ & $\begin{array}{l}\text { Oficializar a política de } \\
\text { desenvolvimento de } \\
\text { coleções }\end{array}$ & Biblioteca & $\begin{array}{l}\text { Gestor da } \\
\text { Biblioteca }\end{array}$ & Curto \\
\hline
\end{tabular}




\begin{tabular}{|c|c|c|c|c|c|}
\hline \\
\hline \multirow{2}{*}{$\begin{array}{l}\text { Como promover } \\
\text { positivamente a } \\
\text { Biblioteca diante } \\
\text { da comunidade e } \\
\text { sua integração } \\
\text { com outras } \\
\text { instituições já } \\
\text { existentes? }\end{array}$} & $\begin{array}{l}\text { Falta de recursos } \\
\text { para materiais de } \\
\text { divulgação }\end{array}$ & $\begin{array}{l}\text { Criar materiais de } \\
\text { divulgação das normas e } \\
\text { serviços da Biblioteca }\end{array}$ & $\begin{array}{l}\text { Materiais de } \\
\text { expediente da } \\
\text { Biblioteca; parceria } \\
\text { com gráficas; } \\
\text { licitação da } \\
\text { Prefeitura } \\
\text { Municipal }\end{array}$ & $\begin{array}{l}\text { Funcionárias } \\
\text { da Biblioteca; } \\
\text { gestor da } \\
\text { Biblioteca }\end{array}$ & $\begin{array}{l}\text { Curto / } \\
\text { Médio }\end{array}$ \\
\hline & $\begin{array}{l}\text { Resistência das } \\
\text { outras } \\
\text { instituições em } \\
\text { firmar parcerias }\end{array}$ & $\begin{array}{l}\text { Firmar parcerias com as } \\
\text { escolas do município para } \\
\text { divulgação dos serviços e } \\
\text { participação nas atividades } \\
\text { oferecidas pela Biblioteca }\end{array}$ & $\begin{array}{l}\text { Biblioteca e } \\
\text { Secretaria de } \\
\text { Educação e Cultura } \\
\text { do Município }\end{array}$ & $\begin{array}{l}\text { Gestor da } \\
\text { Biblioteca; } \\
\text { Secretário de } \\
\text { Educação do } \\
\text { Município; } \\
\text { Diretores de } \\
\text { Escolas }\end{array}$ & Curto \\
\hline $\begin{array}{l}\text { Como promover } \\
\text { uma maior } \\
\text { integração e } \\
\text { comunicação } \\
\text { entre as } \\
\text { funcionárias da } \\
\text { Biblioteca? }\end{array}$ & $\begin{array}{l}\text { Resistência das } \\
\text { funcionárias }\end{array}$ & $\begin{array}{l}\text { Promover reuniões e } \\
\text { eventos para a integração } \\
\text { entre as funcionárias }\end{array}$ & Biblioteca & $\begin{array}{l}\text { Gestor da } \\
\text { Biblioteca }\end{array}$ & Curto \\
\hline $\begin{array}{l}\text { De que forma } \\
\text { pode ser alterada } \\
\text { a visão da } \\
\text { Prefeitura em } \\
\text { relação a } \\
\text { Biblioteca para } \\
\text { valorizá-la }\end{array}$ & $\begin{array}{l}\text { Indiferença e } \\
\text { insensibilidade } \\
\text { dos governantes } \\
\text { às questões } \\
\text { ligadas a } \\
\text { Biblioteca }\end{array}$ & $\begin{array}{l}\text { Elaborar relatórios e } \\
\text { projetos para encaminhar à } \\
\text { Prefeitura Municipal } \\
\text { buscando visibilidade e } \\
\text { apoio }\end{array}$ & Biblioteca & $\begin{array}{l}\text { Gestor da } \\
\text { Biblioteca }\end{array}$ & Médio \\
\hline $\begin{array}{l}\text { Como otimizar as } \\
\text { atividades } \\
\text { realizadas na } \\
\text { Biblioteca, } \\
\text { garantindo sua } \\
\text { eficiência? }\end{array}$ & $\begin{array}{l}\text { Falta de } \\
\text { comprometiment } \\
\text { o da Prefeitura } \\
\text { Municipal com } \\
\text { um orçamento } \\
\text { anual para a } \\
\text { Biblioteca }\end{array}$ & $\begin{array}{l}\text { Construir sede própria para } \\
\text { a Biblioteca }\end{array}$ & $\begin{array}{l}\text { Terreno cedido pela } \\
\text { Prefeitura } \\
\text { Municipal; } \\
\text { investimento } \\
\text { previsto no } \\
\text { orçamento da } \\
\text { Prefeitura } \\
\text { Municipal; } \\
\text { captação de } \\
\text { recursos estaduais e } \\
\text { federais por meio } \\
\text { da Prefeitura }\end{array}$ & $\begin{array}{l}\text { Prefeitura } \\
\text { Municipal de } \\
\text { Palhoça }\end{array}$ & Longo \\
\hline
\end{tabular}

Fonte: os autores

\section{CONSIDERAÇÕES FINAIS}

As bibliotecas públicas brasileiras, em especial as municipais, são instituições que sobrevivem com poucos recursos, assim como a Biblioteca Pública Municipal de Palhoça Guilherme Wiethorn Filho, que não foge a essa regra. No entanto, não são apenas as dificuldades financeiras que impedem que essas unidades de informação desenvolvam as suas potencialidades. $\mathrm{O}$ fato de ter um público amplo e bastante heterogêneo também faz com que o oferecimento de serviços de qualidade seja um desafio. Por esses motivos é necessário planejar as ações da biblioteca, para evitar soluções imediatistas, ineficientes e ineficazes para as demandas emergentes. O estudo sobre questões relacionadas ao planejamento 
estratégico em unidades de informação está sendo ampliado, porém foi possível perceber que o número de experiências de planejamento estratégico em bibliotecas públicas ainda é pequeno.

Para fundamentar o planejamento estratégico é necessário fazer um diagnóstico dos ambientes interno e externo da unidade de informação, a fim de levantar os pontos fortes e fracos da instituição, e as oportunidades e ameaças presentes no ambiente externo.

Nesta pesquisa, a etapa do diagnóstico mostrou-se de extrema importância no levantamento de dados e informações para subsidiar o planejamento da Biblioteca Pública Municipal de Palhoça. Conhecer a realidade da Biblioteca Municipal da Palhoça, a relação que mantém com a instituição mantenedora, as necessidades e percepções dos usuários reais e as necessidades dos usuários potenciais dessa biblioteca foi uma experiência muito rica. Os representantes das associações de bairro mostraram-se disponíveis para falar sobre sua comunidade. Eles forneceram informações úteis, pois conhecem as pessoas do bairro, suas características e comportamentos. Realizar as entrevistas possibilitou um maior conhecimento sobre o estado atual de boa parte do município de Palhoça. Embora tenham sido abrangidas apenas dez associações de bairro, das dezesseis existentes, elas atendem outros bairros vizinhos e refletem a realidade deles.

Durante o desenvolvimento da revisão de literatura e da pesquisa em si constatou-se que para a realização de um planejamento, mesmo na fase de diagnóstico, assim como na elaboração das questões estratégicas, obstáculos e propostas estratégicas, é necessário ter conhecimento teórico e prático sobre administração, isso facilita o processo e amplia as possibilidades de o responsável ter uma visão de todo o contexto da biblioteca. No entanto, para que seja realizado de forma completa, o planejamento estratégico de uma biblioteca pública deve ser feito por uma equipe composta por funcionários da biblioteca e funcionários da instituição mantenedora, dispostos a ouvir a opinião de usuários reais e potenciais. Ademais, é preciso manter todos os funcionários integrados aos processos para motivá-los a participar do planejamento e diminuir a resistência para a mudança.

Espera-se que os resultados desta pesquisa sirvam de instrumento de tomada de decisão e que auxilie no processo de elaboração de um plano de ação detalhado para as estratégias aqui propostas, fazendo com que sejam postas em prática. Contudo, as informações produzidas podem servir para fundamentar ações no sentido de mudar a visão que a sociedade e os governantes têm da Biblioteca foco do estudo, mostrando-a como um elemento essencial para a população e que não é somente vontade de quem já a conhece e utiliza de que ela cresça, mas de todos os moradores do município.

O exemplo apresentado nesta pesquisa pode estimular outras bibliotecas deste mesmo segmento a realizar um estudo mais aprofundado com seus stakeholders e estabelecer um plano adequado a sua realidade. 
Este estudo é simplesmente o ponto de partida para a elaboração de um planejamento estratégico mais completo, que deve ser atualizado de acordo com as constantes mudanças ocorridas na cidade.

Todavia, o caminho ainda é longo para que a Biblioteca Pública Municipal de Palhoça Guilherme Wiethorn Filho seja reconhecida e chegue a um alto nível de qualidade no oferecimento de seus serviços. Mas a partir do momento em que pessoas se comprometerem e aderirem ao planejamento, com visão estratégica, o potencial da Biblioteca poderá ser aumentado por meio do estabelecimento de parcerias e aproveitamento das oportunidades.

\section{REFERÊNCIAS}

ALMEIDA, Maria Christina Barbosa de. Planejamento de bibliotecas e serviços de informação. 2. ed. rev. e ampl. Brasília, DF: Lemos Informação e Comunicação, 2005.

BARBALHO, Célia Regina Simonetti; BERAQUET, Vera Silvia Marão. Planejamento estratégico para unidades de informação. São Paulo: Polis, 1995.

BARDIN, Laurence. Análise de conteúdo. 4. ed. rev. atual. Lisboa: Edições 70, 2009.

BERNARDINO, Maria Cleide Rodrigues; SUAIDEN, Emir José. O papel social da biblioteca pública na interação entre informação e conhecimento no contexto da ciência da informação. Perspectivas em Ciência da Informação, v.16, n.4, p.29-41, out./dez. 2011.

BRASIL. Lei no 12.527 , de 18 de novembro de 2011. Regula o acesso a informações. Diário Oficial [da] União: edição extra. Brasília, DF, 18 nov. 2011. Disponível em: <http://www.planalto.gov.br/ccivil_03/_ato2011-2014/2011/lei/112527.htm>. Acesso em: 27 fev. 2013.

DELORS, Jacques. Educação: um tesouro a descobrir, relatório para a UNESCO da Comissão Internacional sobre educação para o século XXI. 10. ed. São Paulo: Cortez; Brasília, DF: Unesco, 2006.

FUNDAÇÃO BIBLIOTECA NACIONAL. Coordenadoria do Sistema Nacional de Bibliotecas Públicas. Biblioteca pública: princípios e diretrizes. Rio de Janeiro: Fundação Biblioteca Nacional, Dep. de Processos Técnicos, 2000. (Documentos Técnicos, 6).

FUNDAÇÃO BIBLIOTECA NACIONAL. Coordenadoria do Sistema Nacional de Bibliotecas Públicas. Coordenadoria do Sistema Nacional de Bibliotecas Públicas. Biblioteca pública: princípios e diretrizes. 2. ed. Rio de Janeiro: Fundação Biblioteca Nacional, Dep. de Processos Técnicos, 2010. 
GIL, Antonio Carlos. Como elaborar projetos de pesquisa. 5. ed. São Paulo: Atlas, 2010.

IFLA. UNESCO. Manifesto da IFLA/UNESCO sobre bibliotecas públicas. 1994.

Disponível em: <http://archive.ifla.org/VII/s8/unesco/port.htm>. Acesso em: 27 fev. 2013.

KOTLER, Philip. Marketing para organizações que não visam o lucro. São Paulo: Atlas, 1978.

MACIEL, Alba Costa; MENDONÇA, Marília Alvarenga Rocha. Bibliotecas como organizações. Rio de Janeiro: Interciência, 2006.

MILANESI, Luís. A casa da invenção: biblioteca centro de cultura. 4. ed. rev. ampl. Cotia: Ateliê, 2003.

MILANESI, Luís. Ordenar para desordenar: centros de cultura e bibliotecas públicas. São Paulo: Brasiliense, 1986.

OLIVEIRA, Djalma de Pinho Rebouças de. Planejamento estratégico: conceitos, metodologia, práticas. 27. ed. São Paulo: Atlas, 2010.

PAULO, Erli. Biblioteca Pública Municipal De Palhoça Guilherme Wiethorn Filho: 30 anos construindo sua história. 2005. 42p. Monografia (Especialização em Gestão de Bibliotecas) - Curso de Especialização em Gestão de Bibliotecas, Universidade do Estado de Santa Catarina, Florianópolis, 2005.

ROMANI, Claudia; BORSZCZ, Iraci (Orgs.). Unidades de informação: conceitos e competências. Florianópolis: UFSC, 2006.

SANTOS, Paloma Maria; BERNARDES, Marciele Berger; ROVER, Aires José. Teoria e prática de governo aberto: lei de acesso à informação nos executivos municipais da Região Sul. Florianópolis: Funjab, 2012.

TAKAHASHI, Tadao (Org.). Sociedade da informação no Brasil: livro verde. Brasília: Ministério da Ciência e Tecnologia, 2000.

\section{Como citar este documento:}

SPUDEIT, Daniela Fernanda Assis de Oliveira; KLÖPPEL, Jéssica Vilvert. Subsídios para o planejamento estratégico em bibliotecas públicas: estudo de caso na Biblioteca Municipal de Palhoça/SC. Revista Digital de Biblioteconomia e Ciência da Informação, Campinas, SP, v. 13, n. 2, p. 386- 403, maio/ago. 2015. ISSN 1678-765X. Disponível em: <http://periodicos.bc.unicamp.br/ojs/index.php/rdbci/article/view/8635037>. Acesso em: 31 maio 2015. 